\title{
Towards Autonomous Energy-Wise RObjects
}

\author{
Florian Vaussard ${ }^{1}$, Michael Bonani ${ }^{1}$, Philippe Rétornaz ${ }^{1}$, Alcherio Martinoli $^{2}$, \\ and Francesco Mondada ${ }^{1}$ \\ 1 EPFL - STI - LSRO \\ Station 9, 1015 Lausanne, Switzerland \\ firstname.lastname@epfl.ch \\ 2 EPFL - ENAC - IIE - DISAL \\ Station 2, 1015 Lausanne, Switzerland
}

\begin{abstract}
In this article, the RObject concept is first introduced. This is followed by a survey of applicable energy scavenging technologies. Energy is a key issue for the large scale deployment of robotics in daily life, as recharging the batteries places a considerable burden on the end-user and is a waste of energy which has an overall negative impact on the limited resources of our planet. We show how the energy obtained from light, water flow, and human work, could be promising sources of energy for powering low-duty devices. To assess the feasibility of powering future RObjects with technologies, tests were conducted on commonly available robotic vacuum cleaners. These tests established an upper-bound on the power requirements for RObjects. Finally, based on these results, the feasibility of powering RObjects using scavenged energy is discussed.
\end{abstract}

Keywords: Autonomous RObjects, Energy scavenging, Robotic vacuum cleaner, Power awareness

\section{Introduction}

Struck by the absence of the so-often promised robotic technology in our daily life, the project "Robots for daily life" funded by the "NCCR Robotics" 3 has undertaken a new approach. Instead of creating new robots capable of stateof-the-art Human Robot Interactions - such as speech or face recognition - the RObject concept aims at embedding useful robotic technologies within everydaylife objects. This process relies on the "everyday object" feeling and build upon existing, natural interactions. In addition, this has the advantage of easing the overall conception, referred by Pfeifer as "cheap design" [23]. We foresee RObjects to enhance the long-term interactions between robotic devices and users [12]. The RObject concept has been successfully demonstrated by the creation of robotic glasses [32]. These glasses are able to move by themselves, for example, to be refilled when they are empty. The user still keeps the control on them, using natural interactions, such as lifting the glass. Possible RObjects include,

\footnotetext{
${ }^{3}$ National Competence Center for Research in robotics, a Swiss national coordination effort in robotics
} 
but are not limited to, tableware, furniture, storage spaces, lightening systems, decorative plants, or even room dividers.

If RObjects prove to be successful, they will spread inside our houses. This article addresses the energetic sustainability of such an approach. In term of autonomy and recharge, RObjects face the same energetic challenges as mobile robots. In addition, they introduce the constraint of their large quantity and diffusion inside the house. This aspect, if not properly addressed, can transform this dream into a nightmare.

In Sec. 2, we will present the available scavenging technologies. Section 3 will discuss further the dream of self-powered objects, by assessing an upper-bound on the power requirements using common robotic vacuum cleaners as a model. Finally, Sec. 4 will discuss the promising opportunities and the challenges which remain in designing useful, energy-wise, RObjects.

\section{Energy Scavenging Technologies}

Wasted energy is environmentally ubiquitous and represents a potentially cheap source of power. We will present a short survey of available power technologies, with an emphasis on renewable energies in indoor environments. Comprehensive books and state-of-the-art already exist [2,26,29,34], but usually focus on energies that are unavailable to us.

Scavenging the energy required to move a robot has often been considered in previous works, but at present, only a few people have managed to power an autonomous mobile robot using an energy scavenger. This is due to the small power density available. This issue is theoretically addressed for the case of outdoor unmanned vehicles [39], and concludes with the possibility of using solar and kinetic flow energies to power devices in the range of $1 \sim 10 \mathrm{~W}$. Solar power is commonly used in outer space exploration robots [6]. The EcoBot-II is quite original, in the sense that it embeds a microbial fuel cell converting unrefined insect biomass into electricity [19]. This is however just enough energy to allow it to travel a few centimeters.

Most of the envisioned RObjects will have to move around, implying higher energetic needs. But wheels are not always mandatory. By exploiting the interactions already in-place between the humans and those specific objects, the humans can be used as a transportation vector, thus lowering the requirements, by use of the parasitic mobility concept [16]. For example, the above-cited robotic glasses are used like normal glasses most of the time, except for when they need to be refilled. Thus, we could expect a fairly low duty-cycle operation. Another complementary option, as discussed in the Sec. 4, is to focus on RObjects favoring locations where the power can be easily scavenged.

\section{$2.1 \quad$ Heat}

Heat is a universal source of energy around us, part of the wasted power generated by thermal engines and exhausts, by poorly insulated buildings and even by 
the human body. Thermal energy scavenging devices are primarily ruled by the laws of thermodynamic. Their efficiency $\eta$ is inherently limited by the Carnot cycle [14]

$$
\eta_{C}=\frac{T_{H}-T_{C}}{T_{H}}=\frac{\Delta T}{T_{H}},
$$

where $T_{H}$ and $T_{C}$ are the temperatures of the hot and cold sides respectively. The temperature gradient $\Delta T$ should be maximized, favoring applications such as in the automotive or electronics cooling industries. Making use of thermal gradients is, however, not well suited for obtaining energy under ambient conditions. For example, when applied to scavenge energy between the human body $\left(T_{H}=309 \mathrm{~K}\right)$ and the ambient air $\left(T_{L}=293 \mathrm{~K}\right)$, the maximum achievable efficiency is only $5.2 \%$.

The total efficiency will moreover be lowered by the non-ideal transducer. Thermoelectricity is the most widely used solid-state technology at low temperature. As presented by Min in [2, Chap. 5], ThermoElectric Generators (TEG) are mainly based on the Seebeck effect. A temperature gradient $\Delta T$ applied to a junction will generate a voltage $V_{a b}$, following

$$
V_{a b}=\alpha_{a b} \Delta T,
$$

where $\alpha_{a b}$ is the Seebeck coefficient of the considered junction. Optimizing a TEG is first a matter of material engineering. For ambient temperatures, with $\mathrm{Bi}_{2} \mathrm{Te}_{3}$ used in the case of the human body, the expected overall efficiency falls around $0.91 \%$.

Seiko was the first company to release a watch powered by the human body heat [13]. Using this strategy, it is also feasible to power wearable sensor nodes, providing about $100 \mu \mathrm{W}$ when placed on the wrist [17]. A TEG half-buried in the soil can provide up-to $1 \mathrm{~W} \mathrm{~m}^{-2}$ (peak) to an outdoor sensor node, by exploiting the temperature difference between the buried side and the side exposed to the ambient air [14].

\section{$2.2 \quad$ Light}

The sun is a huge source of energy, which can be easily exploited by solar cells, at least during daylight. Indoor, room lighting is another ubiquitous source of energy. The first calculators to rely solely on this source were designed in the 1980's already [35]. There are some discrepancies in the literature regarding the peak power levels available from the solar spectrum. The most widely used values are presented in Table $1[2,22,34]$. The Air Mass (AM) 1.5 model, used as a reference when testing solar panels, considers a value of $1000 \mathrm{~W} \mathrm{~m}^{-2}$.

The efficiency of solar cells is quite low and depends on a number of factors: ray angles, illumination level [41] - which depends on the season and time of the day - and spectral source. The optimal technology thus depends on the available light. Single crystal silicon is proposed for outdoor conditions, with common efficiencies around 15 to 20\% [10]. Thin film amorphous silicon or cadmium telluride cells are proposed for indoor conditions [34], but they can scavenge a 
Table 1. Available and scavenged power densities from light.

\begin{tabular}{|c|c|c|}
\hline $\begin{array}{l}\text { Raw } \\
\text { Power }\end{array}$ & $\begin{array}{l}\text { Scavenged } \\
\text { Power }\end{array}$ & Conditions \\
\hline $500-1000 \mathrm{~W} \mathrm{~m}^{-2}$ & $200 \mathrm{~W} \mathrm{~m}^{-2}(20 \%)$ & Outdoors - Sunny \\
\hline $100 \quad \mathrm{~W} \mathrm{~m}^{-2}$ & $15 \mathrm{~W} \mathrm{~m}^{-2}(15 \%)$ & Outdoors - Cloudy \\
\hline $1-5 \quad \mathrm{~W} \mathrm{~m}^{-2}$ & $0.1 \mathrm{~W} \mathrm{~m}^{-2}(10 \%)$ & Indoors \\
\hline
\end{tabular}

mere $10 \%$ [30]. Expected power densities at the output of the cells are also given in Table 1.

Other technologies, like the dye sensitized cells and the multi-gap cells, have also been studied. This latter technology is promising since efficiency is increased by multiple band gaps which allow for the capture of photons from a wider range of energies making use of more of the solar spectrum.

Exploration robots mainly use the solar power. For example, the Mars rover "Spirit" is powered by triple-junction cells, providing $190 \mathrm{~W}\left(150 \mathrm{~W} \mathrm{~m}^{-2}\right)$ operating under good conditions [6]. The small robot Alice has been powered using only thin film amorphous silicon cells and a 3000 lumens projector, with an achieved power density of $27.8 \mathrm{~W} \mathrm{~m}^{-2}$ [4]. Finally, wireless sensor nodes can use efficiently the power of small solar cells [11,27].

\subsection{Ambient Radio Frequencies}

Currently, wireless transmissions and various RF emissions are everywhere: TV, radio, cellphones and many others. It would be tempting to exploit part of this radiated power to power RObjects.

The Friis equation [37] can be used to compute the received power $P_{r}$ in an antenna with gain $G_{r}$, assuming a wave of wavelength $\lambda$ emitted at a distance $d$ by an isotropic source of gain $G_{t}$ and propagating in free space, far enough from the emitter (far field condition)

$$
P_{r}=G_{r} G_{t} P_{0}\left(\frac{\lambda}{4 \pi d}\right)^{2}=G_{r} \frac{(E \lambda)^{2}}{4 \pi Z_{0}},
$$

where the radiation impedance of free space, $Z_{0}$, equals 377 ohms. $P_{0}$ is the emitted power, while $E$ is the field strength. When considering indoor conditions, the received power is closer to $P_{r} \sim d^{-4}$. Assuming a unity gain and a field strength of $1 \mathrm{~V} \mathrm{~m}^{-1}$ at $2.4 \mathrm{GHz}$, the scavenged power is around $3.3 \mu \mathrm{W}$.

While the scavenged power is too low for our use - apart from actively transmitting energy using microwaves or a laser [7] - this is enough for wireless sensor nodes [24] or RFID tags, even at a distance of a few meters [21].

\subsection{Pressure and Temperature Variations}

The daily atmospheric changes could also power devices. This technology has been in use since the early 1900's, providing power to clocks [31], and more 
recently to watches [25], based on a closed dilating volume. However, apart from the watch industry, no other device has been powered by this kind of energy.

In fact, according to [5], a variation of $1 \mathrm{~K}$ or $400 \mathrm{~Pa}$ provides $3.5 \cdot 10^{-3} \mathrm{~J}$ of energy. This would be enough to power a small device with a consumption of $50 \mu \mathrm{W}$ for only 70 seconds. This is however enough to power the Atmos clock for 2 days, implying a power consumption of only $20 \mathrm{nW}$.

\subsection{Gas and Liquid Flows}

Flow has for long been exploited to scavenge energy in wind and watermills. This energy is also available inside houses, hidden in air breezes generated by air-conditioning or heating systems, as well as in water pipes. This principle is, for example, exploited by the self-powered shower handle [1].

According to the Betz' law, for a flow of speed $v$ considered over a surface $A$, only $59.3 \%$ of the total power can be scavenged

$$
P_{\text {max }}=C_{P} \cdot P_{\text {flow }}=C_{p} \cdot \frac{1}{2} \rho A v^{3} \quad \text { where } C_{p}=\frac{16}{27} \approx 0.59 .
$$

The power is proportional to the flow density $\rho$. Air and water have respective densities of 1.2 and $1000 \mathrm{~kg} \mathrm{~m}^{-3}$. The available power is around 0.35 and $290 \mathrm{~W} \mathrm{~m}^{-2}$ for a flow speed of $1 \mathrm{~m} \mathrm{~s}^{-1}$. Water is undoubtedly more powerful.

Even if big mills tend to have an efficiency close to the Betz limit, small devices operating at low speeds suffer from increased mechanical and viscous friction, reducing their efficiency to about $1 / 6$ of the Betz limit [20]. To scavenge energy from the air flow, most researchers are using a custom rotor coupled with a standard DC motor operating in generator mode [8,28], even powering sensor nodes $[9,36]$.

\subsection{Mechanical}

Mechanical scavenging is a broad topic, with numerous applications $[3,40]$. However, up until now, no robot has been powered in this manner. Sensor nodes are better suited, by example for monitoring the stress of life-critical materials .

Several technologies are currently being studied. Electromagnetic generators are quite popular, but are difficult to integrate on MEMS devices. Piezoelectric scavengers convert a stress into a voltage, often using a PZT ceramic. Finally, electrostatic devices are based on a variable capacitor, operated either at fixed voltage or fixed charge.

In the home environment, possible mechanical energy sources include machine vibrations such as clothes dryers and microwave ovens, as well as low amplitude vibrations like structural vibrations of the windows and walls [33]. The available power is however low compared to industrial applications (engines, machine tools), on the order of $0.3 \mathrm{~mW} \mathrm{~cm}^{-3}$.

For our RObject concept, scavenging human power could be an interesting solution. Scavenging the power of the human gait could produce up to a few Watts [38], but scavenging too much energy would result in a disturbance for 
the user. The first research focused on shoes, producing up to $230 \mathrm{~mW}$ [15]. Piezoelectric scavengers implemented in pavements and roads are another option. A prototype [18] is said to produce $3.8 \mathrm{~W}$ with a walking person.

As RObjects will closely interact with humans, they could also benefit from this interaction by scavenging some power. Based on the work of the gravity force, the energy involved is around $E=m g h$. For a lightweight RObject, this would result only in a few Joules, which is not enough for our needs. The work of the friction force, $E=\mu m g d$, is of the same order of magnitude.

\section{RObjects Power Requirements}

It is clear that scavenging energy for use in powering RObjects is a real possibility. Establishing the energy needs for RObjects and determining an upper bound is crucial to the design of real, autonomous RObjects. This upper-bound has to be representative of an all-purpose mobile robotic system. The previously mentioned moving glasses are not well suited, as they have inefficient stepper motors and perform only small displacements. A more representative device is the robotic vacuum cleaner, now a well established technology. Vacuuming is a typical domestic task, like tidying the house, watering the plants or feeding the cat. All have about the same duty cycle (a few hours per week) and energy requirements.

We have compared several vacuum cleaners with respect to their power consumption, as well as to their performance and efficiency. The tested systems are shown in Fig. 1. The robots differ from the hand-operated vacuum cleaner mainly by their localization and path planning process, but also by their cleaning tools.

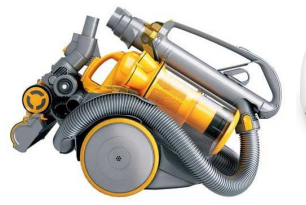

(a)

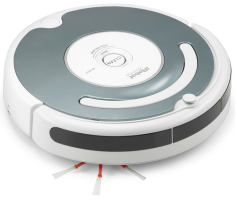

(b)

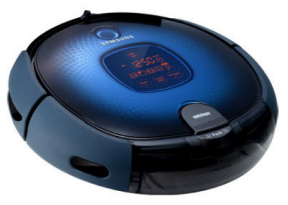

(c)

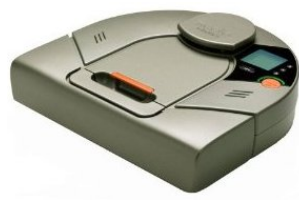

(d)

Fig. 1. Tested vacuum cleaners. Hand-operated (Dyson DC05) (a), iRobot Roomba 530 (b), Samsung Navibot (c) and Neato XV-11 (d).

The Roomba has no global localization and relies only on basic displacement patterns (line, circle, wall following), coupled with a simple IR-based detection of the base station. Starting from 2010, two new affordable challengers have appeared. The Navibot is sold by Samsung and relies on an upward-looking camera doing Visual Simultaneous Localization And Mapping (V-SLAM). The XV-11 is sold by Neato Robotics and performs regular SLAM using a cheap laser scanner. 
A fake house environment has been built inside our testing facility, as pictured in Fig. 2 (a). The floor is a standard, smooth, industrial grade one, with some minor defects. The efficiency of these vacuums on carpet is not tested since locomotion is not the focus of this article.

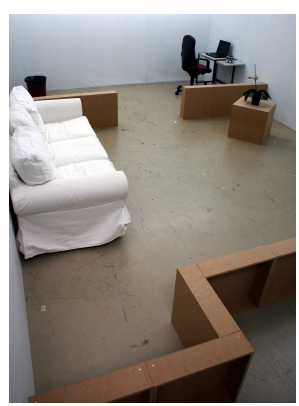

(a)

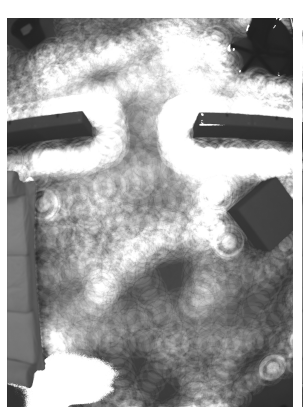

(b) Roomba @ 984s

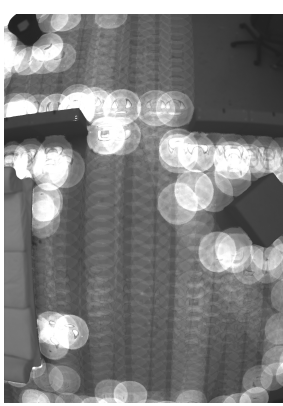

(c) Navibot @ 984 s

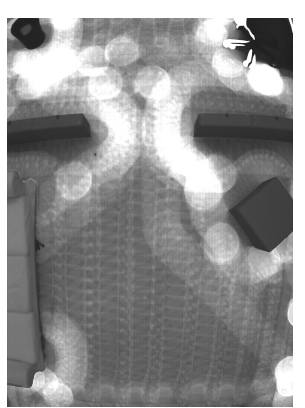

(d) Neato @ $984 \mathrm{~s}$

Fig. 2. (a) Testing environment. (b) - (d) Composite images, took with the overhead camera at $2.18 \mathrm{~Hz}$, at completion by the Neato $(984 \mathrm{~s})$. The base station is located in the bottom right corner.

Preliminary experiments were conducted in occupied homes and have shown a mean deposition ratio for the dirt of $0.5 \mathrm{~g} \mathrm{~m}^{-2}$ for a whole week. The surface of our arena is roughly $25 \mathrm{~m}^{2}$. We have used a mixture of $20 \mathrm{~g}$ of flour and $10 \mathrm{~g}$ of breadcrumb, simulating the result of two busy weeks of activity in a home without vacuuming. The amount of dust was measured for all the experimental steps using a differential methodology coupled with a Metler precision scale, which has a resolution of $0.001 \mathrm{~g}$. The robots were thoroughly cleaned before each run.

The results are shown in Table 2, while composite images are shown in Fig. 2 (b) - (d). The whiter the area, the more often the robot stayed or passed. All three robots have about the same speed. The difference between the Roomba and the two other robots is obvious. The Roomba cleans several times the same spot, while the two others are more systematic. The Neato is slightly more efficient around the obstacles (sofa and alike), as it can plan ahead difficulties with its laser scanner.

The idle power consumptions $P_{s}$ and $P_{s r}$ are measured using a precision Wattmeter. The figures are really high, especially when the charged robot is connected to its base station $\left(P_{s r}\right)$, indicating a huge loss of energy. For each run, the cleaning time was measured directly, while the required energy has been inferred based on the energy consumed during a complete charge. The influence of the idle consumption $P_{s r}$ has been removed beforehand, but the charge losses are still included. The robot operational power is simply computed based on $P_{o p}=E / T$. 
Table 2. Results for manual and robotic vacuum cleaners.

\begin{tabular}{|c|c|c|c|c|c|c|c|c|c|}
\hline \multirow[b]{3}{*}{ Units } & \multirow{3}{*}{\multicolumn{2}{|c|}{\begin{tabular}{cc}
\multicolumn{2}{c}{ Idle power } \\
Station & Station \\
only & + robot \\
$P_{s}$ & $P_{s r}$ \\
$\mathrm{~W}$ & $\mathrm{~W}$
\end{tabular}}} & \multicolumn{7}{|c|}{ Statistics for each run } \\
\hline & & & \multicolumn{2}{|c|}{$\begin{array}{l}\text { Cleaning } \\
\text { time } \\
T\end{array}$} & \multicolumn{2}{|c|}{$\begin{array}{c}\text { Energy } \\
E\end{array}$} & \multirow{2}{*}{$\begin{array}{c}\text { Robot } \\
\text { Power } \\
P_{o p} \\
\text { W }\end{array}$} & \multicolumn{2}{|c|}{$\begin{array}{l}\text { Collected } \\
\text { dust }^{a}\end{array}$} \\
\hline & & & $\mathrm{s}$ & $m-m^{b}$ & $\mathrm{~kJ}$ & $m-m^{b}$ & & $\%$ & $m-m^{b}$ \\
\hline Dysc & - & - & 390 & 36 & 474.0 & 43. & $1215^{c}$ & 97.4 & 0.005 \\
\hline Roomba & 1.14 & 4.80 & 3674 & 482 & 96.5 & 12.7 & 26.3 & 80.8 & 3.89 \\
\hline Navibot $^{d}$ & 1.77 & 7.75 & 1264 & 44 & 51.9 & 1.81 & 41.0 & 48.9 & 4.92 \\
\hline Neato & 0.33 & 4.50 & 930 & 92 & 33.8 & 3.34 & 36.3 & 80.4 & 2.29 \\
\hline Neato (2 times) & 0.33 & 4.50 & 2067 & 38 & 75.1 & 1.38 & 36.3 & 92.8 & 2.67 \\
\hline
\end{tabular}

${ }^{a}$ This includes both the dust collected in the bin and on other parts of the robot

${ }^{b} \max -\min$

${ }^{c}$ Measured directly using a Wattmeter

${ }^{d}$ Used in "Edge" mode, for better results

Several interesting facts should be pointed out. First, cleaning using a robot requires far less energy than doing it by hand, by a factor 5 to 14 . Even if a robot takes more time to do its job, its power consumption is nevertheless 30 to 45 times smaller. The cleaning efficiency of the robots is a step behind the classical vacuum cleaner, and is really bad in the case of the Navibot. The Roomba and Neato have a dust efficiency around $80 \%$, while Roomba takes 4 times longer and provides incomplete floor coverage as can be seen in Fig. 2 (e). As shown with the Neato, the efficiency can be improved by executing a second pass. Almost $93 \%$ of the dust was collected this way. These results are only a few percent worse than those obtained by the conventional vacuum cleaner. Finally, the Navibot is pretty inefficient overall, but the test conditions were quite harsh for such small robots.

Compared to someone vacuuming once a week, using the Neato twice a week would allow him to spare $80 \%$ of the energy, while keeping the dirt level low. It would even be possible to use the Neato everyday and still using only $50 \%$ of the power required to vacuum by hand once a week.

The superiority of the Neato undoubtedly stems from its use of the SLAM method coupled with an efficient brush - aspiration system. It has, however, two drawbacks. The most important one is the noise, which is simply unbearable. And the absence of a side brush results in a poor cleaning of the borders and corners. A good compromise would be to combine the SLAM provided by the Neato with the cleaning functions of the Roomba.

\section{Conclusion and Discussion}

An exhaustive summary of scavenging technologies is given in Table 3. Not surprisingly, water and solar power are the most powerful sources, along with 
the human gait. Scavenging a water flow could be really interesting, but a free flow is not common inside a house, apart from devices like fountains or shower handles. Indoor lighting is common, but would provide only a small amount of power.

Table 3. Summary of scavenging technologies. Base units are $\mathrm{mW}$ and $\mathrm{cm}$ for an easier comparison at the RObject scale.

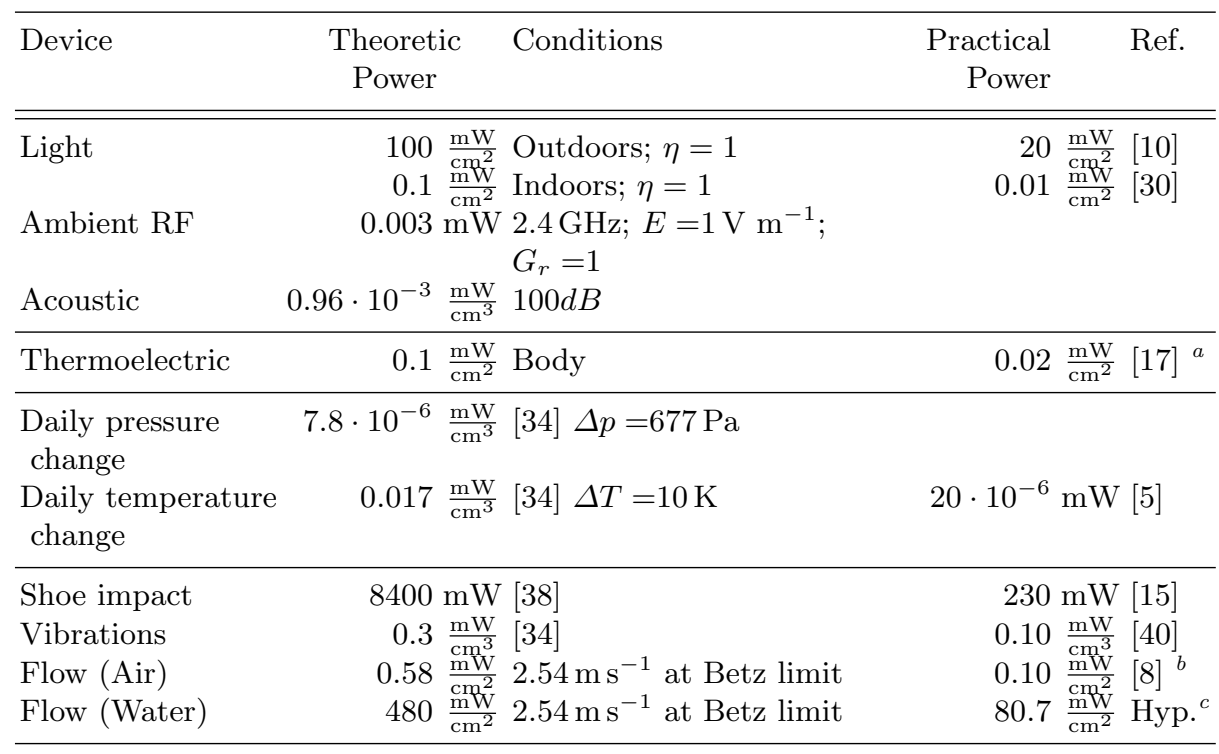

${ }^{a}$ On the wrist

b $2.54 \mathrm{~m} \mathrm{~s}^{-1}$

${ }^{c} 2.54 \mathrm{~m} \mathrm{~s}^{-1} ; 1 / 6$ of Betz limit

Concerning energy consumption and based on our tests, we can assume as a reasonable case a $30 \mathrm{~W}$ RObject, used for two hours per week. This model would represent a consumption of $60 \mathrm{Wh}$ per week. Table 4 shows the feasibility of this case, with some of the energy scavenging devices presented in Table 3, mounted on the robot and / or on the base station. An optimized RObject, with good brushless motors and well crafted electronics, would probably consume far less energy than this worst case.

From this analysis, it is clear that powering such a RObject would be feasible. The first choice is a small solar panel operated outdoors. When used indoors, this solar panel should be placed just behind a window in direct sunlight. Even if part of the power will be reflected and absorbed by the glass, a bigger solar panel should still suffice. This will have to be assessed in our future work.

The second choice is to find an application operating near a water source. This would be a good solution for RObjects having a low power consumption, as 
Table 4. Possible power sources for a RObject consuming $60 \mathrm{~W}$ h per week.

\begin{tabular}{|c|c|c|c|c|c|}
\hline Source & $\begin{array}{l}\text { Power } \\
\text { Density }\end{array}$ & $\begin{array}{l}\text { Duration } \\
\text { per Day }\end{array}$ & $\begin{array}{c}\text { Energy } \\
\text { per Week }\end{array}$ & $\begin{array}{l}\text { Feasibility } \\
\text { Condition }\end{array}$ & Feasible? \\
\hline $\begin{array}{l}\text { Solar } \\
\text { (outdoors) }\end{array}$ & $10.00 \frac{\mathrm{mW}}{\mathrm{cm}^{2}}$ & $8 \mathrm{~h}$ & $560.00 \frac{\mathrm{mWh}}{\mathrm{cm}^{2}}$ & $1 \mathrm{dm}^{2}$ & Yes \\
\hline $\begin{array}{l}\text { Solar } \\
\text { (indoors) }\end{array}$ & $0.01 \frac{\mathrm{mW}}{\mathrm{cm}^{2}}$ & $8 \mathrm{~h}$ & $0.56 \frac{\mathrm{mW} \mathrm{h}}{\mathrm{cm}^{2}}$ & $10 \mathrm{~m}^{2}$ & No \\
\hline Vibrations & $0.10 \frac{\mathrm{mW}}{\mathrm{cm}^{3}}$ & $24 \mathrm{~h}$ & $16.80 \frac{\mathrm{mWh}}{\mathrm{cm}^{3}}$ & $0.35 \mathrm{~m}^{3}$ & No \\
\hline Human gait & $200.00 \mathrm{~mW}$ & $2 \mathrm{~h}$ & $2.10 \mathrm{Wh}$ & $\begin{array}{l}\text { Several } \\
\text { humans }\end{array}$ & Maybe \\
\hline Air & $0.10 \frac{\mathrm{mW}}{\mathrm{cm}^{2}}$ & $24 \mathrm{~h}$ & $16.80 \frac{\mathrm{mWh}}{\mathrm{cm}^{2}}$ & $35 \mathrm{~m}^{2}$ & No \\
\hline Water & $80.00 \frac{\mathrm{cm}}{\mathrm{cm}^{2}}$ & $1 \mathrm{~h}$ & $560.00 \frac{\mathrm{mW} h}{\mathrm{~cm}^{2}}$ & $1 \mathbf{d m}^{2}$ & Maybe \\
\hline
\end{tabular}

a reasonable propeller is enough. The last choice is to scavenge mechanical power from human movement, by fitting carpets with mechanical scavenging devices, placed in high-traffic areas. This also sounds interesting, but would require to adapt the human environment.

As a conclusion, this study has provided excellent initial data and analysis. This allows a better understanding of the potential performances and limitations of robotics in term of energy, especially with respect to the long term vision of an intensive use in our daily life. The solar energy is for sure one of the best options to ensure zero-energy robotic systems. We could, for example, design a water-pouring RObject to take care of the houseplants. Or even design moving plants able to take care of themselves, both from the water and sun point of view. Tables and chairs are also often placed in a bright place, and RObjects furniture could be of a great help, for example to increase efficiency when vacuuming.

Low-duty RObjects powered by energy scavenging devices seem imminently feasible. We however have to design them to be energy efficient and cost effective if we want them to reach the market. The robots of Sec. 3 are designed to be cheap, thus their consumption is above state-of-the-art low power robots. This will be one of the main focus of our work on future RObjects, as energy is a scarce resource. Even if the scavenging device shall not suffice by itself to cover all the needs, it will have a great impact in the energetic balance, if it is well designed. Providing such a RObject will be our next step.

Acknowledgments. This research was supported by the Swiss National Science Foundation through the National Centre of Competence in Research Robotics.

\section{References}

1. Bean, J.: Energy saving shower head (Jun 9 2005), US Patent App. 11/148,524 
2. Beeby, S., White, N.: Energy Harvesting for Autonomous Systems. Artech House Publishers (2010)

3. Beeby, S., Tudor, M., White, N.: Energy harvesting vibration sources for microsystems applications. Measurement science and technology 17, R175 (2006)

4. Boletis, A., Driesen, W., Breguet, J., Brunete, A.: Solar Cell Powering with Integrated Global Positioning System for mm3 Size Robots. In: Intelligent Robots and Systems, 2006 IEEE/RSJ International Conference on. pp. 5528-5533. IEEE (2007)

5. Callaway, E.: Wireless sensor networks: architectures and protocols. CRC press (2004)

6. Crisp, J., Adler, M., Matijevic, J., Squyres, S., Arvidson, R., Kass, D.: Mars exploration rover mission. Journal of Geophysical Research 108(E12), 8061 (2003)

7. Denninghoff, D., Starman, L., Kladitis, P., Perry, C.: Autonomous powerscavenging MEMS robots. In: Circuits and Systems, 2005. 48th Midwest Symposium on. pp. 367-370. IEEE (2006)

8. Federspiel, C., Chen, J.: Air-powered sensor. In: Sensors, 2003. Proceedings of IEEE. vol. 1, pp. 22-25. IEEE (2004)

9. Flammini, A., Marioli, D., Sardini, E., Serpelloni, M.: An autonomous sensor with energy harvesting capability for airflow speed measurements. In: Instrumentation and Measurement Technology Conference (I2MTC), 2010 IEEE. pp. 892-897. IEEE (2010)

10. Green, M., Emery, K., Hishikawa, Y., Warta, W.: Solar cell efficiency tables (version 34). Progress in Photovoltaics: Research and Applications 17(5), 320-326 (2009)

11. Hande, A., Polk, T., Walker, W., Bhatia, D.: Indoor solar energy harvesting for sensor network router nodes. Microprocessors and Microsystems 31(6), 420-432 (2007)

12. Kaplan, F.: Everyday robotics: robots as everyday objects. In: Proceedings of the 2005 joint conference on Smart objects and ambient intelligence: innovative context-aware services: usages and technologies. pp. 59-64. ACM (2005)

13. Kishi, M., Nemoto, H., Hamao, T., Yamamoto, M., Sudou, S., Mandai, M., Yamamoto, S.: Micro thermoelectric modules and their application to wristwatches as an energy source. In: Thermoelectrics, 1999. Eighteenth International Conference on. pp. 301-307. IEEE (2002)

14. Knight, C., Davidson, J.: Thermal Energy Harvesting for Wireless Sensor Nodes with Case Studies. Advances in Wireless Sensors and Sensor Networks pp. 221-242 (2010)

15. Kymissis, J., Kendall, C., Paradiso, J., Gershenfeld, N.: Parasitic power harvesting in shoes. In: Wearable Computers, 1998. Digest of Papers. Second International Symposium on. pp. 132-139 (1998)

16. Laibowitz, M., Paradiso, J.: Parasitic mobility for pervasive sensor networks. Pervasive Computing pp. 255-278 (2005)

17. Leonov, V., Torfs, T., Fiorini, P., Van Hoof, C.: Thermoelectric converters of human warmth for self-powered wireless sensor nodes. Sensors Journal, IEEE 7(5), 650 657 (2007)

18. Mandal, I., Patra, P.: Renewable Energy Source. International Journal of Computer Applications IJCA 1(17), 44-53 (2010)

19. Melhuish, C., Ieropoulos, I., Greenman, J., Horsfield, I.: Energetically autonomous robots: Food for thought. Autonomous Robots 21(3), 187-198 (2006)

20. Mitcheson, P., Yeatman, E., Rao, G., Holmes, A., Green, T.: Energy harvesting from human and machine motion for wireless electronic devices. Proceedings of the IEEE 96(9), 1457-1486 (2008) 
21. Obrist, B., Hegnauer, S.: A microwave powered data transponder. Sensors and Actuators A: Physical 46(1-3), 244-246 (1995)

22. O'Donnell, T., Wang, W.: Power Management, Energy Conversion and Energy Scavenging for Smart Systems. Ambient Intelligence with Microsystems pp. 241266 (2009)

23. Pfeifer, R., Bongard, J., Grand, S.: How the body shapes the way we think: a new view of intelligence. The MIT Press (2007)

24. Philipose, M., Smith, J., Jiang, B., Mamishev, A., Roy, S., Sundara-Rajan, K.: Battery-free wireless identification and sensing. IEEE Pervasive Computing pp. 37-45 (2005)

25. Phillips, S.: Temperature responsive self winding timepieces (Oct 1 2002), US Patent $6,457,856$

26. Priya, S., Inman, D.J.: Energy Harvesting Technologies. Springer Publishing Company, Incorporated, 1st edn. (2008)

27. Raghunathan, V., Kansal, A., Hsu, J., Friedman, J., Srivastava, M.: Design considerations for solar energy harvesting wireless embedded systems. In: Information Processing in Sensor Networks, 2005. IPSN 2005. Fourth International Symposium on. pp. 457-462. IEEE (2005)

28. Rancourt, D., Tabesh, A., Fréchette, L.: Evaluation of centimeter-scale micro windmills: aerodynamics and electromagnetic power generation. Proc. PowerMEMS 2007 pp. 28-29 (2007)

29. Randall, J.: Designing indoor solar products. Wiley Online Library (2006)

30. Randall, J., Jacot, J.: The performance and modelling of 8 photovoltaic materials under variable light intensity and spectra. In: World Renewable Energy Conference VII Proceedings, Cologne, Germany (2002)

31. Reutter, J.: Horloge à remontage automatique par les variations de température ou de pression atmosphérique (Jan 15 1929), Swiss Patent CH130941A

32. Rey, F., Leidi, M., Mondada, F.: Interactive mobile robotic drinking glasses. Distributed Autonomous Robotic Systems 8 pp. 543-551 (2009)

33. Roundy, S., Wright, P., Rabaey, J.: A study of low level vibrations as a power source for wireless sensor nodes. Computer Communications 26(11), 1131-1144 (2003)

34. Roundy, S., Wright, P., Rabaey, J.: Energy scavenging for wireless sensor networks: with special focus on vibrations. Springer Netherlands (2004)

35. Sangani, K.: The sun in your pocket. Eng. Technol 2(8), 36-38 (2007)

36. Sardini, E., Serpelloni, M.: Self-powered wireless sensor for air temperature and velocity measurements with energy harvesting capability. Instrumentation and Measurement, IEEE Transactions on PP(99), 1 -7 (2010)

37. Smith, A.: Radio Frequency Principles \& Applications. Universities Press (1998)

38. Starner, T.: Human-powered wearable computing. IBM Systems Journal 35(3\&4) (1996)

39. Thomas, J., Qidwai, M., Kellogg, J.: Energy scavenging for small-scale unmanned systems. Journal of Power sources 159(2), 1494-1509 (2006)

40. Op het Veld, B., Hohlfeld, D., Pop, V.: Harvesting mechanical energy for ambient intelligent devices. Information Systems Frontiers 11(1), 7-18 (2009)

41. Virtuani, A., Lotter, E., Powalla, M.: Influence of the light source on the lowirradiance performance of $\mathrm{Cu}$ (In, Ga) Se2 solar cells. Solar Energy Materials and Solar Cells 90(14), 2141-2149 (2006) 